\title{
Differentiation between Cystic Pituitary Adenomas and Rathke Cleft Cysts: A Diagnostic Model Using MRI
}

\author{
M. Park, S.-K. Lee, J. Choi, S.-H. Kim, S.H. Kim, N.-Y. Shin, J. Kim, and S.S. Ahn
}

\begin{abstract}
BACKGROUND AND PURPOSE: Cystic pituitary adenomas may mimic Rathke cleft cysts when there is no solid enhancing component found on MR imaging, and preoperative differentiation may enable a more appropriate selection of treatment strategies. We investigated the diagnostic potential of MR imaging features to differentiate cystic pituitary adenomas from Rathke cleft cysts and to develop a diagnostic model.
\end{abstract}

MATERIALS AND METHODS: This retrospective study included 54 patients with a cystic pituitary adenoma (40 women; mean age, 37.7 years) and 28 with a Rathke cleft cyst (18 women; mean age, 31.5 years) who underwent MR imaging followed by surgery. The following imaging features were assessed: the presence or absence of a fluid-fluid level, a hypointense rim on T2-weighted images, septation, an off-midline location, the presence or absence of an intracystic nodule, size change, and signal change. On the basis of the results of logistic regression analysis, a diagnostic tree model was developed to differentiate between cystic pituitary adenomas and Rathke cleft cysts. External validation was performed for an additional 16 patients with a cystic pituitary adenoma and 8 patients with a Rathke cleft cyst.

RESULTS: The presence of a fluid-fluid level, a hypointense rim on T2-weighted images, septation, and an off-midline location were more common with pituitary adenomas, whereas the presence of an intracystic nodule was more common with Rathke cleft cysts. Multiple logistic regression analysis showed that cystic pituitary adenomas and Rathke cleft cysts can be distinguished on the basis of the presence of a fluid-fluid level, septation, an off-midline location, and the presence of an intracystic nodule $(P=.006, .032, .001$, and .023 , respectively). Among 24 patients in the external validation population, 22 were classified correctly on the basis of the diagnostic tree model used in this study.

CONCLUSIONS: A systematic approach using this diagnostic tree model can be helpful in distinguishing cystic pituitary adenomas from Rathke cleft cysts.

ABBREVIATIONS: AUC $=$ area under the curve; $\mathrm{RCC}=$ Rathke cleft cyst

$\mathrm{P}$ ituitary adenoma is a benign neoplasm that arises from the adenohypophysis and is the most common intrasellar pathology, accounting for $10 \%-15 \%$ of all intracranial neoplasms. ${ }^{1,2}$ Typical imaging findings of an uncomplicated pituitary adenoma include slow enhancement compared with that of the pituitary gland, lateral deviation of the infundibulum, and isointense signal intensity relative to gray matter on T1-weighted imaging. ${ }^{3}$ Intratumoral hem-

Received December 2, 2014; accepted after revision February 24, 2015. From the Department of Radiology, Research Institute of Radiological Science (M.P., S.-K.L., J.K., S.S.A.), Biostatistics Collaboration Unit, Medical Research Center (J.C.), and Departments of Neurosurgery (S.-H.K.) and Pathology (S.H.K.), Yonsei University College of Medicine, Seoul, South Korea; and Department of Radiology (N.-Y.S.), Ewha Womans University School of Medicine, Seoul, South Korea.

Please address correspondence to S.S. Ahn, MD, PhD, Department of Radiology, Research Institute of Radiological Science, Yonsei University College of

Medicine, 50 Yonsei-ro, Seodaemun-gu, 120-752 Seoul, South Korea;

e-mail: sungsoo@yuhs.ac

http://dx.doi.org/10.3174/ajnr.A4387 orrhage and ischemic infarction are common with larger pituitary adenomas, which may result in hemorrhagic or cystic changes or both, leading to various signal intensities on MR imaging. ${ }^{4-8}$

Rathke cleft cyst (RCC) is a benign epithelial cyst believed to originate from the remnants of the Rathke pouch. ${ }^{9}$ Typical imaging findings include a nonenhancing, noncalcified, intrasellar/ suprasellar cyst with an intracystic nodule. ${ }^{9-12}$ Depending on its cystic content and the presence of an associated intracystic nodule, an RCC may show various signal intensities on both T1- and T2-weighted images. ${ }^{13-15}$ More specifically, T1 hyperintensity and T2 hypointensity of an RCC associated with a high intracystic protein content can mimic cystic pituitary adenoma with hemorrhage, which makes imaging diagnosis of a cystic pituitary adenoma or an RCC a challenge.

Preoperative differentiation between a cystic pituitary adenoma and an RCC is important for treatment planning. ${ }^{16-18}$ Par- 
Table 1: Demographic and clinical data of patients with a cystic pituitary adenoma or Rathke cleft cyst

\begin{tabular}{|c|c|c|c|}
\hline Patient Data & $\begin{array}{c}\text { Cystic Pituitary } \\
\text { Adenomas }(n=54)\end{array}$ & $\begin{array}{l}\text { Rathke Cleft } \\
\text { Cysts }(n=28)\end{array}$ & $P$ Value $^{\mathrm{a}}$ \\
\hline Age (mean $\pm S D$ ), y & $37.7 \pm 11.4$ & $31.5 \pm 12.7$ & .026 \\
\hline Sex, male/female ratio & $14: 40$ & 10:18 & .362 \\
\hline Size of tumor/cyst (mean $\pm S D$ ), mm & $18.4 \pm 7.9$ & $19.2 \pm 5.5$ & .644 \\
\hline Suprasellar extension, $n(\%)$ & $31(57.4)$ & $19(67.8)$ & .358 \\
\hline Abnormal hormone level, $n$ (\%) & 49 (90.7) & $25(89.3)$ & .833 \\
\hline \multicolumn{4}{|l|}{ Symptoms, $n(\%)$} \\
\hline Local mass effect & $11(20.4)$ & $13(46.3)$ & .014 \\
\hline Hormonal symptoms & $18(33.3)$ & $8(28.6)$ & .660 \\
\hline Headache & $14(25.9)$ & $7(25.0)$ & .927 \\
\hline
\end{tabular}

Note:-SD indicates standard deviation

${ }^{a}$ From the $\chi^{2}$ test.

tial resection of the wall and evacuation of cyst contents are sufficient for an RCC, whereas a cystic pituitary adenoma may require total resection, not only to relieve mass effect but also to correct hormone excess. ${ }^{9,19-21}$ Unnecessary surgical excision of an RCC may lead to serious complications, such as CSF leaks, infection, and hypothalamic injury, though the incidences thereof are very low. ${ }^{21,22}$ Thus, obtaining the correct preoperative diagnosis with which to determine the proper surgical indication and to plan the optimal surgical procedure is a major concern for neurosurgeons. ${ }^{9}$ To date, several characteristic MR imaging appearances of pituitary adenomas and RCCs have been reported, 2,9,12,20,23-25 but there are some cases for which the diagnoses are inconclusive when 1 or 2 imaging findings are used, and none of the studies has systemically analyzed the MR imaging appearances of cystic pituitary adenomas to differentiate them from RCCs. Therefore, we evaluated the diagnostic potential of a multifactor analysis of MR imaging findings and developed a diagnostic tree model to increase the diagnostic accuracy in differentiating cystic pituitary adenomas and RCCs before surgery.

\section{MATERIALS AND METHODS Study Population}

This retrospective study was approved by the Yonsei University Health System institutional review board, and the requirement for informed consent was waived. We retrospectively reviewed preoperative MR imaging and electronic medical records. Among 891 patients with a sellar mass who underwent surgery between August 2007 and July 2013, we identified 82 patients (24 men and 58 women; mean [ \pm standard deviation] age, $35.6 \pm 12.1$ years) with a lack of solid enhancement or thin-rim enhancement $(<2$ $\mathrm{mm}$ ) on preoperative MR imaging. Among them, 54 patients (14 men and 40 women; mean age, $37.7 \pm 11.4$ years $)$ were diagnosed with a pituitary adenoma and 28 patients (10 men and 18 women; mean age, $31.5 \pm 12.7$ years) were diagnosed with an RCC on the basis of histopathology reports. None of the included pituitary adenomas involved the cavernous sinus. Craniopharyngioma was not included for analysis, because only 3 patients presented with a cystic mass without a solid enhancing portion during the same period, and 2 of them had typical imaging findings of craniopharyngioma. Those 54 patients with a pituitary adenoma underwent surgery because of medication treatment failure $(n=10)$, local mass effect $(n=11)$, hormonal symptoms $(n=18)$, headache $(n=14)$, or rapid size increase $(n=1)$. Twenty-eight patients with an RCC underwent surgery because of local mass effect $(n=$

\section{Validation Population}

\section{Data Acquisition}

\section{Image Analysis}

13), hormonal symptoms $(n=8)$, or headache $(n=7)$. Laboratory and immunohistochemical findings (available for 26 patients) revealed that 46 patients had a hormonally functioning adenoma with prolactin (32 cases), growth hormone (8 cases), adrenocorticotropic hormone (5 cases), or thyroid-stimulating hormone (1 case). In the other 8 patients, the adenoma was nonfunctioning, with or without hypopituitarism. The characteristics of the 82 patients are shown in Table 1 .

For validation, an additional 24 patients (10 men and 14 women; mean age, $38.8 \pm 15.8$ years) with a cystic pituitary adenoma $(n=16)$ or an RCC $(n=8)$ histopathologically confirmed between August 2013 and August 2014 were subsequently included in the study.

Each of the preoperative MR imaging examinations of the sella was performed with a 3T MR unit using an 8-channel head coil (Achieva; Philips Healthcare, Best, the Netherlands). The following pulse sequences were acquired: sagittal T2-weighted imaging (TE, $3000 \mathrm{~ms}$; TR, $80 \mathrm{~ms}$; section thickness, $3 \mathrm{~mm}$; matrix, $400 \times$ 316; and FOV, $23 \times 23 \mathrm{~cm}$ ), sagittal T1-weighted imaging (TR, $2000 \mathrm{~ms}$; TE, $10 \mathrm{~ms}$; section thickness, $2-3 \mathrm{~mm}$; matrix, $256 \times$ 200; and FOV, $23 \times 23 \mathrm{~cm}$ ), axial T2-weighted imaging (TR, 3000 $\mathrm{ms}$; TE, $80 \mathrm{~ms}$; section thickness, $5 \mathrm{~mm}$; matrix $400 \times 309$; and FOV, $23 \times 23 \mathrm{~cm}$ ), and coronal T2-weighted imaging (TR, 2129.8 ms; TE, $90 \mathrm{~ms}$; section thickness, 1-2 mm; matrix, $368 \times 368$; and FOV , $18 \times 18 \mathrm{~cm}$ ). Five coronal T1-weighted dynamic images (TR, $230 \mathrm{~ms}$; TE, $15 \mathrm{~ms}$; section thickness, 2-3 mm; matrix, $352 \times$ 351 ; and FOV, $20 \times 20 \mathrm{~cm}$ ) were obtained every $25-30$ seconds after an intravenous bolus injection $(0.2 \mathrm{~mL} / \mathrm{kg})$ of gadoliniumbased contrast (gadoterate meglumine [Dotarem; Guerbet, Aulnay-sous-Bois, France]), followed by coronal T1-weighted imaging (TR, $2000 \mathrm{~ms}$; TE, $10 \mathrm{~ms}$; section thickness, $2 \mathrm{~mm}$; matrix, $320 \times 240$; and FOV, $20 \times 20 \mathrm{~cm}$ ) and sagittal T1-weighted imaging (TR, $2000 \mathrm{~ms}$; TE, $10 \mathrm{~ms}$; section thickness, $2 \mathrm{~mm}$; matrix, $320 \times 250$; and FOV, $20 \times 20 \mathrm{~cm}$ ).

Two radiologists (one with 5 years and one with 1 year of experience in neuroradiology) who were blinded to the final histologic diagnosis independently analyzed the imaging of each patient to document the following findings: presence of a fluid-fluid level, hypointense rim on T2-weighted images, septation, off-midline location, presence of an intracystic nodule, change in size, and change in signal intensity (Fig 1). 2,9,12,20,23-25 The presence or absence of a fluid-fluid level was evaluated on either axial or sagittal T2-weighted images. A peripheral hypointense rim was regarded as present if the peripheral portion of a sellar lesion was lower than the signal intensity of white matter on T2-weighted images. Septation was identified on axial or coronal T2-weighted images and/or on contrast-enhanced T1-weighted images. Offmidline location was defined as lateralization of the lesion in the 

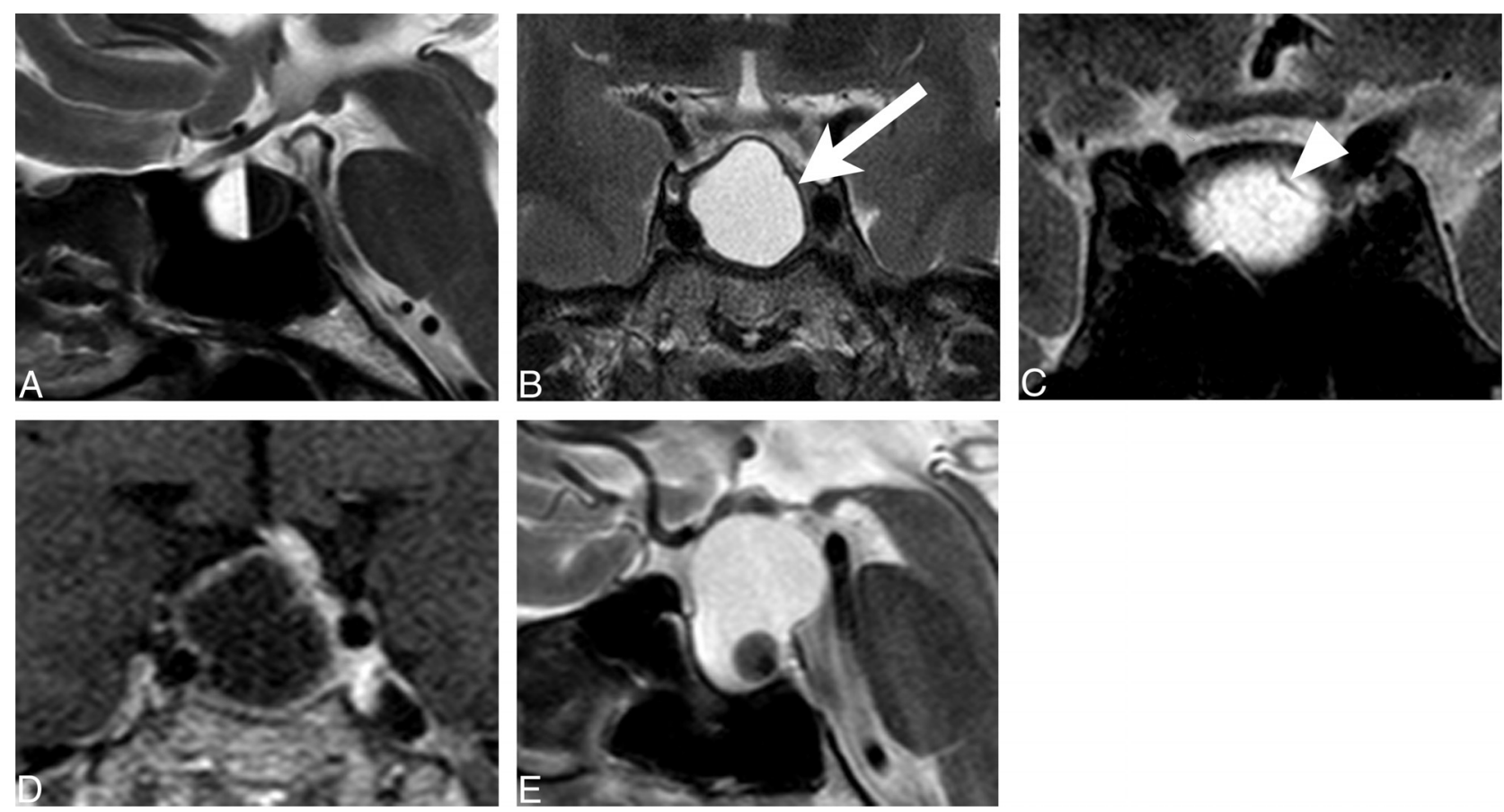

FIG 1. Typical MR features for image analysis: $A$, fluid-fluid level (sagittal T2-weighted image); $B$, peripheral hypointense rim (arrow) (coronal T2-weighted image); $C$, septation (arrowhead) (coronal T2-weighted image); $D$, off-midline location, deviating pituitary stalk (coronal contrastenhanced T1-weighted image); and $E$, intracystic nodule (sagittal T2-weighted image).

sella turcica or stalk deviation by the lesion. An intracystic nodule was defined as a nodule showing various signal intensities on T1- and T2-weighted images without enhancement after contrast-medium administration. A size change (either increase or decrease) or signal change was defined as present if there was any change in size or signal intensities on T1- and T2-weighted images between the 2 preoperative MR imaging examinations, when previous MR imaging examinations were performed $(n=78)$. The median follow-up interval for all the cases was 59 days (interquartile range, 26-126 days), for adenomas $(n=55)$ it was 58 days (interquartile range, 26-154 days), and for RCCs $(n=23)$ it was 62 days (interquartile range, 27-98 days). Interobserver agreement for the imaging findings was assessed, and discordant interpretations were resolved by consensus.

For the validation group, the significant MR imaging findings in the study group were evaluated for differentiation. Two radiologists (one with 5 years and one with 1 year of experience in neuroradiology) who were blinded to the final histopathologic diagnoses performed imaging analyses on the basis of the diagnostic tree model.

\section{Review of Imaging Reports}

Each official radiologic report had been written by several neuroradiologists with $>5$ years' experience in neuroradiology and was reviewed retrospectively. Final impressions of the radiologic reports were recorded to compare them with those of the diagnostic tree model in terms of diagnostic accuracy. When there were several differential diagnoses on the reports, only the first impression was used for analysis.

\section{Statistical Analysis}

Statistical analyses were performed by using the software package $\mathrm{R}$ version 3.0.2 (http://www.R-project.org) and MedCalc version 9.3.6.0 (MedCalc Software, Mariakerke, Belgium). The interobserver agreement for each imaging feature was calculated by using the $\kappa$ statistic. A $\kappa$ value of $0.81-1.0$ indicated excellent agreement between the 2 observers, $0.61-0.80$ indicated good agreement, $0.41-0.60$ indicated moderate agreement, $0.21-0.40$ indicated fair agreement, and $0-0.20$ indicated only slight agreement. The frequencies of imaging features of cystic pituitary adenomas and those of RCCs were compared with $\chi^{2}$ tests. The contribution of each imaging feature was evaluated by univariate logistic regression and a multivariable logistic regression model after a stepwise procedure was performed to differentiate cystic pituitary adenomas and RCCs. On the basis of the results of logistic regression analysis, a recursivepartitioning-tree classification algorithm was used to suggest a diagnostic tree model. Finally, the discriminatory powers of the diagnostic tree model and radiologic reports were assessed by receiver operating characteristic analysis, and the areas under the curve (AUCs) for receiver operating characteristic analysis were compared. A $P$ value of $<.05$ was considered statistically significant.

\section{RESULTS}

Interobserver agreements for imaging features were good to excellent, with $\kappa$ values of 0.780 for the presence of a fluid-fluid level, 0.677 for a hypointense rim on T2-weighted images (Fig 2), 1.0 for septation, 0.926 for an off-midline location, and 0.892 for the presence of an intracystic nodule.

The frequencies of MR imaging findings were significantly different between pituitary adenomas and RCCs. The presence of a fluid-fluid level, a hypointense rim on T2-weighted images, an 

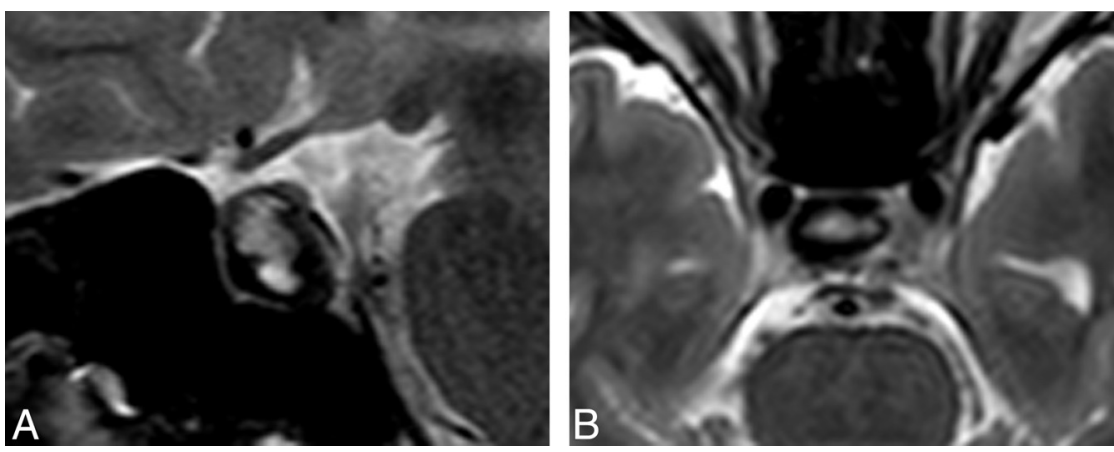

(Figs 5 and 6). In terms of diagnosing pituitary adenomas, the sensitivity and specificity of the diagnostic tree model were $98.1 \%$ and $92.9 \%$ and those of the official radiologic reports were $77.8 \%$ and $92.9 \%$, respectively. Receiver operating characteristic curve analyses were performed to compare the AUCs between the diagnostic tree model and those of the official radiologic reports. The AUC values were 0.991 for the diagnostic tree model and 0.853 for the radiologic reports, and the difference was statistically significant $(P<.001)$ (Fig 4).

image of a 27 -year-old woman with a pituitary adenoma, which was misinterpreted as a fluid-fluid level on axial T2-weighted images by one reader. B, Later, a hypointense rim on a T2-weighted image was agreed on consensually.

Table 2: MR imaging features of cystic pituitary adenomas and Rathke cleft cysts

\begin{tabular}{|c|c|c|c|}
\hline Variable & $\begin{array}{l}\text { Cystic Pituitary } \\
\text { Adenomas } \\
(n=54)(n[\%])\end{array}$ & $\begin{array}{c}\text { Rathke Cleft } \\
\text { Cysts (n=28) } \\
(n[\%])\end{array}$ & $P$ Value $^{\mathrm{a}}$ \\
\hline Fluid-fluid level & $37(68.5)$ & $1(3.6)$ & $<.001$ \\
\hline Hypointense rim on $\mathrm{T} 2$ & $41(75.9)$ & $6(21.4)$ & $<.001$ \\
\hline Septation & $21(38.9)$ & $1(3.6)$ & .002 \\
\hline Off-midline location & $45(83.3)$ & $2(7.1)$ & $<.001$ \\
\hline Intracystic nodule & $9(16.7)$ & $19(67.9)$ & $<.001$ \\
\hline Size change & $24(44.4)$ & $8(28.6)$ & .212 \\
\hline Increase & $20(37.0)$ & $3(10.7)$ & .012 \\
\hline Decrease & $4(7.4)$ & $5(17.9)$ & .151 \\
\hline Signal change & $20(37.0)$ & $4(14.3)$ & .05 \\
\hline
\end{tabular}

${ }^{a}$ From the $\chi^{2}$ test.

off-midline location, septation, and signal change of the lesion were more common with pituitary adenomas than with RCCs (Table 2). An intracystic nodule in the lesion was observed significantly more often in RCCs than in pituitary adenomas.

Receiver operating characteristic curve analyses were performed, and the following 3 variables exhibited good performances in diagnosing cystic pituitary adenomas: the presence of a fluid-fluid level (sensitivity, 68.5\%; specificity, 96.4\%; AUC value, 0.825 ), a hypointense rim on T2-weighted images (sensitivity, 75.9\%; specificity, 78.6\%; AUC value, 0.773 ), and an off-midline location (sensitivity, 83.3\%; specificity, 92.9\%; AUC value, 0.881 ). The presence of an intracystic nodule also exhibited good performance in diagnosing RCCs (sensitivity, 83.3\%; specificity, 67.9\%; AUC value, 0.756).

The ORs from the univariate logistic regression analysis of MR imaging variables for predicting cystic pituitary adenomas are listed in Table 3. Multiple logistic regression analysis with a stepwise procedure was performed to identify the MR imaging variables that contributed to the differentiation of cystic pituitary adenomas from RCCs. The presence of a fluid-fluid level, septation, and an off-midline location were selected as independent factors associated with cystic pituitary adenomas and the presence of an intracystic nodule as associated with RCCs. These variables and their adjusted ORs are listed in Table 3.

Using the recursive-partitioning analysis based on the classification and regression tree method, ${ }^{26}$ we were able to establish a diagnostic tree model (Fig 3). The diagnostic tree model was able to correctly classify 79 (96.3\%) of 82 cases in the study population
The proposed diagnostic tree model was then validated on subsequent data from the 24 patients in the external-validation group. There were no significant differences between the study group and the validation group in terms of age, sex, or histopathology results $(P=.252, P=.119$, and $P=.762$, respectively). The imaging diagnoses made by 2 radiologists on the basis of the diagnostic tree model agreed for all the patients. Twenty-two of these 24 cases were classified correctly (91.7\%) (Figs 5 and 6). One RCC was misclassified as a cystic pituitary adenoma because of septation (Fig 7), and one cystic pituitary adenoma was misclassified as an RCC because of its midline location and the absence of a fluid-fluid level and septation.

\section{DISCUSSION}

We first evaluated the diagnostic value of imaging findings for differentiating cystic pituitary adenomas and RCCs. Consistent with previous reports, ${ }^{3,8,20,27}$ we found that the presence of a fluid-fluid level, septation, and an off-midline location strongly favored a diagnosis of cystic pituitary adenoma over that of RCC. Conversely, the presence of an intracystic nodule was associated significantly with RCCs. On the basis of these results, we established a diagnostic tree model that increased the diagnostic accuracy for differentiating cystic pituitary adenomas from RCCs by using preoperative MR imaging. The use of this model with MR imaging findings resulted in the correct classification of $>95 \%$ of the study cases and $91.7 \%$ of the validation cases. Given its availability and simplicity, we believe that this method has important clinical implications for making correct preoperative diagnoses and determining the proper treatment planning.

RCCs are sometimes indistinguishable from cystic pituitary adenomas on MR imaging, and a previous study reported that $50 \%$ of surgically proven RCCs were misdiagnosed as pituitary adenomas preoperatively because of their various signal intensities, which ranged from hypointense to hyperintense on both T1and T2-weighted images. ${ }^{15}$ These various MR signal intensities depend on the composition of the cyst, including protein, mucopolysaccharides, and cholesterol. ${ }^{15,28}$ Another study reported that wall enhancement of cystic lesions may play a role in differentiating neoplastic from nonneoplastic cysts. ${ }^{29}$ However, RCCs are often surrounded by the enhancing normal pituitary gland, thus mimicking wall enhancement, especially when there is a partial volume-averaging effect. ${ }^{11}$ In addition, RCCs may show patchy or 
Table 3: Potential predicting variables for pituitary adenomas on MR imaging using logistic regression analysis

\begin{tabular}{|c|c|c|c|c|}
\hline \multirow[b]{2}{*}{ Variable } & \multicolumn{2}{|c|}{ Univariate Analysis } & \multicolumn{2}{|c|}{ Multivariate Analysis $^{a}$} \\
\hline & Crude OR $(95 \% \mathrm{Cl})$ & $P$ Value & Adjusted OR (95\% CI) & $P$ Value \\
\hline Fluid-fluid level & $58.76(7.36-468.94)$ & $<.001$ & $165.42(4.42-6190.89)$ & .006 \\
\hline Hypointense rim on $\mathrm{T} 2$ & $11.56(3.86-34.65)$ & $<.001$ & & \\
\hline Septation & 17.18 (2.17-136.08) & .007 & 48.00 (1.39-1653.33) & .032 \\
\hline Off-midline location & $65.0(13.04-323.97)$ & $<.001$ & 71.73 (5.55-926.93) & .001 \\
\hline Intracystic nodule & $0.09(0.03-0.28)$ & $<.001$ & $0.037(0.002-0.63)$ & .023 \\
\hline Suprasellar extension & $1.63(0.6-4.09)$ & .449 & & \\
\hline Size change & $2.00(0.75-5.33)$ & .170 & & \\
\hline Increase & $4.52(1.21-16.96)$ & .025 & & \\
\hline Decrease & $2.717(0.67-11.07)$ & .163 & & \\
\hline Signal change & $3.53(1.07-11.65)$ & .038 & & \\
\hline
\end{tabular}

${ }^{a}$ Multivariate analysis after stepwise procedure.

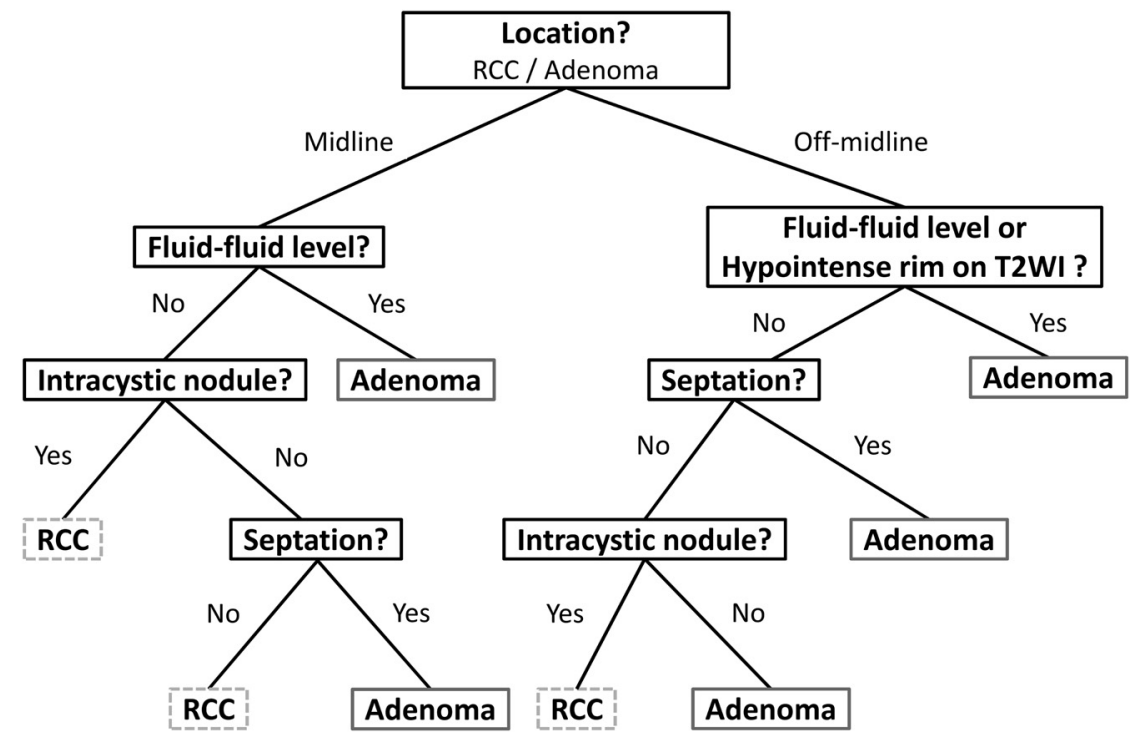

FIG 3. Diagnostic decision tree for the differentiation of cystic pituitary adenomas and RCCs using MR imaging.

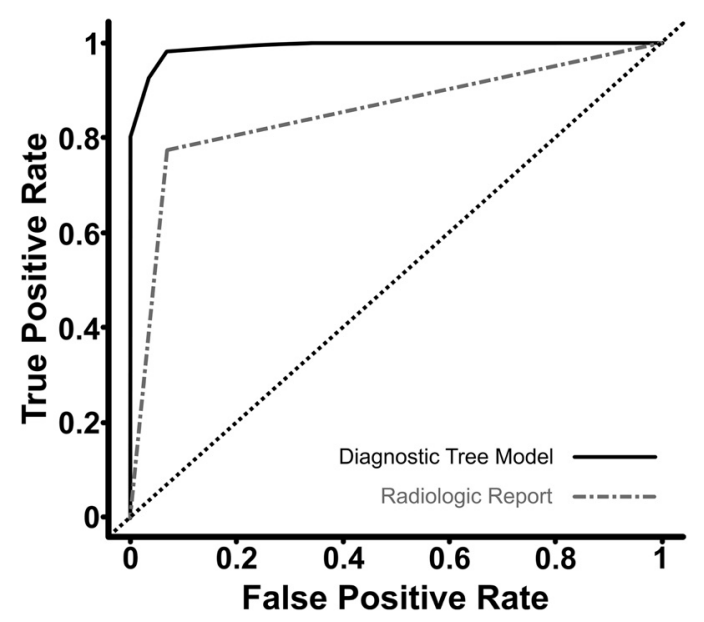

FIG 4. Receiver operating characteristic curve comparison between the diagnostic decision tree model and official radiologic report for the differentiation of cystic pituitary adenomas and Rathke cleft cysts.

ring enhancement, which can be attributed to inflammation and/or squamous metaplasia in the cyst wall. ${ }^{15}$ The presence of an intracystic nodule has been suggested as a characteristic MR imaging feature of RCCs, with an incidence of $37.5 \%-45 \%{ }^{9,13}$
Although intracystic nodules were more common in RCCs than in cystic pituitary adenomas, we also observed intracystic nodules in pituitary adenomas (67.9\% vs $16.7 \%$, respectively). Moreover, these nodules can easily be mistaken for hemorrhage and vice versa, which makes the preoperative differentiation between RCCs and cystic pituitary adenomas problematic. ${ }^{30}$

The presence of a fluid-fluid level, presumably related to intracystic hemorrhage, was significantly more common in, and had high predictive value for, cystic pituitary adenomas. Intratumoral hemorrhage in pituitary adenomas is common even without clinical symptoms. ${ }^{7,31,32}$ Thus, clinical symptoms themselves are not always sufficient to make a correct diagnosis of hemorrhagic adenoma. Furthermore, hemorrhagic pituitary adenomas can exhibit various signal intensities on both T1- and T2-weighted MR imaging, which makes imaging diagnoses difficult. More accurate diagnoses can be achieved by considering other imaging parameters collectively.

An off-midline location was the most important imaging finding for distinguishing pituitary adenomas from RCCs on the basis of multivariate logistic regression analysis in our study, which may be explained by their different ori-

gins. RCCs are believed to originate from the remnants of the Rathke pouch and are located mainly in the midline of the pituitary gland. ${ }^{9}$ Conversely, adenomas arise from the adenohypophysis, and the 2 most common pituitary adenomas, prolactinomas and growth hormone-secreting adenomas, tend to arise laterally in the sella turcica. ${ }^{10,33}$ Thus, lateral bulging of the gland and displacement of the infundibulum were considered characteristic findings of pituitary adenomas. ${ }^{3,27}$ However, adrenocorticotropic hormone-secreting adenomas are often located at the midline, which may overlap with the location of RCCs. ${ }^{33}$ In our study, an off-midline location alone showed high diagnostic value, but that value could be improved when combined with other imaging parameters via a diagnostic tree model.

In this study, cystic pituitary adenomas and RCCs did not have a significant size change difference. Several reports have indicated that some RCCs undergo reduction without treatment and even resolve spontaneously, which suggests that simple RCCs may be dynamic in nature. ${ }^{18,30,34}$ Although growth rates are variable, pituitary adenomas usually enlarge slowly over years and may also exhibit size change, even regression, accompanied by intratumoral hemorrhage and resorption. ${ }^{4,10,31}$ We also observed that size increases were more frequent in cystic pituitary adenomas than in RCCs, but on the basis of multivariate analysis, size in- 

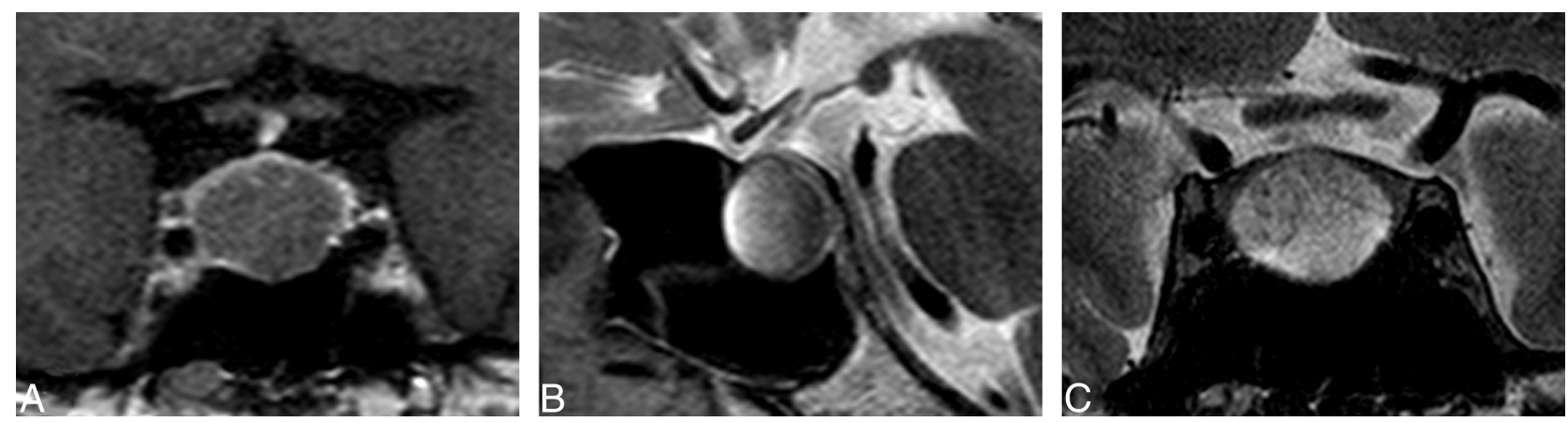

FIG 5. A 71-year-old female patient presented with a 21.2-mm nonenhancing intrasellar cystic lesion. The lesion was located in the midline on a coronal contrast-enhanced T1-weighted image $(A)$, and a fluid-fluid level $(B)$ and septation $(C)$ were seen on sagittal and coronal T2-weighted images. This lesion was classified as a cystic pituitary adenoma on the basis of the diagnostic tree model and was finally diagnosed by histopathology as a pituitary adenoma.
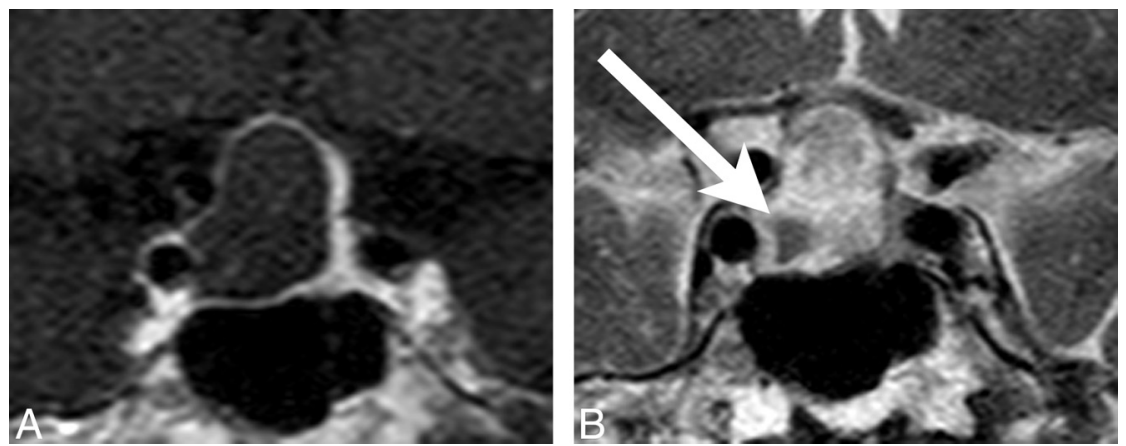

FIG 6. A 42-year-old male patient presented with a 23.8-mm nonenhancing sellar and suprasellar lesion. The cystic lesion had an off-midline location on contrast-enhanced T1-weighted imaging $(A)$ and an intracystic nodule (arrow) showing hypointensity on coronal T2-weighted imaging (B). There was no identified fluid-fluid level or septation. Therefore, this lesion was classified as a Rathke cleft cyst on the basis of the diagnostic tree model and was diagnosed through histopathology as a Rathke cleft cyst.

creases did not have predictive value for diagnosing cystic pituitary adenomas.

Clinical findings could be important clues for making a preoperative diagnosis. However, preoperative endocrine dysfunction was reported in up to $80 \%$ of patients with an RCC, which makes diagnosis with clinical findings alone difficult. ${ }^{9,35}$ In our study, the incidence of hormonal symptoms was $28.6 \%$, which was less common than in previous studies but not significantly different than that of cystic pituitary adenomas (33.3\%), which supports the idea that radiologic findings are important when making a preoperative diagnosis.

Previously, T2*-weighted imaging was proposed as a potential way to detect intratumoral hemorrhage in pituitary adenomas. ${ }^{7}$ Another study in which diffusion-weighted MR imaging was used revealed that the ADC values of RCCs were significantly higher than those of other cystic lesions, including cystic or hemorrhagic pituitary adenomas; therefore, diffusion-weighted MR imaging may be useful for differentiating cystic lesions in the pituitary fossa. ${ }^{36}$ However, these sequences are not routinely performed for standard sellar MR imaging because of susceptibility artifacts related to the skull base and, thus, were not performed in our patients. In this study, features of conventional T1- and T2-weighted MR imaging were evaluated without the need for any additional advanced imaging techniques. Our proposed diagnostic tree model with a combination of imaging features (ie, an off-midline location, the presence of a fluid-fluid level or a hypointense rim on $\mathrm{T} 2$ weighted MR imaging, septation, and the presence of an intracystic nodule) is easy to use and can achieve high diagnostic performance (AUC value, 0.991), which is significantly superior to that of the original radiologic reports (AUC value, 0.853). Furthermore, it can suggest which imaging features should be considered more important than the others in differentiating cystic pituitary adenomas and RCCs. In addition, the diagnostic tree model showed high diagnostic performance in the validation group by the radiologists with 5 years or 1 year of experience, which suggests that radiologists with less experience may also benefit from the systematic approach for differentiating cystic pituitary adenomas and RCCs.

Our study had several limitations. It was a retrospective study with a possible selection bias. We excluded pituitary adenomas with an enhancing solid portion, which may indicate that these results cannot be generalized to all pituitary adenomas and RCCs that show typical imaging features. However, the purpose of this study was to differentiate pituitary adenomas that present as cystic lesions from RCCs. Therefore, we proposed a diagnostic tree model that is easily applicable in clinical situations when a cystic mass without solid enhancement in the sella is observed and surgical treatment is considered because of the patient's symptoms. Because this study was retrospective, we were not able to correlate the findings of each image with pathology results. In addition, we did not include craniopharyngioma, another common pathology in this region. RCCs and craniopharyngiomas have been suggested to be on a histologic continuum, and the differentiation of these lesions is often difficult, even at the microscopic and molecular levels. ${ }^{37}$ However, in the study period, there were only 3 cases of craniopharyngiomas that presented as cystic masses without a solid enhancing portion, and 2 of them showed imaging findings typical of craniopharyngioma. The number of patients in this study was relatively small, but significant differences in MR imaging findings were found between the cystic pituitary adenomas and 

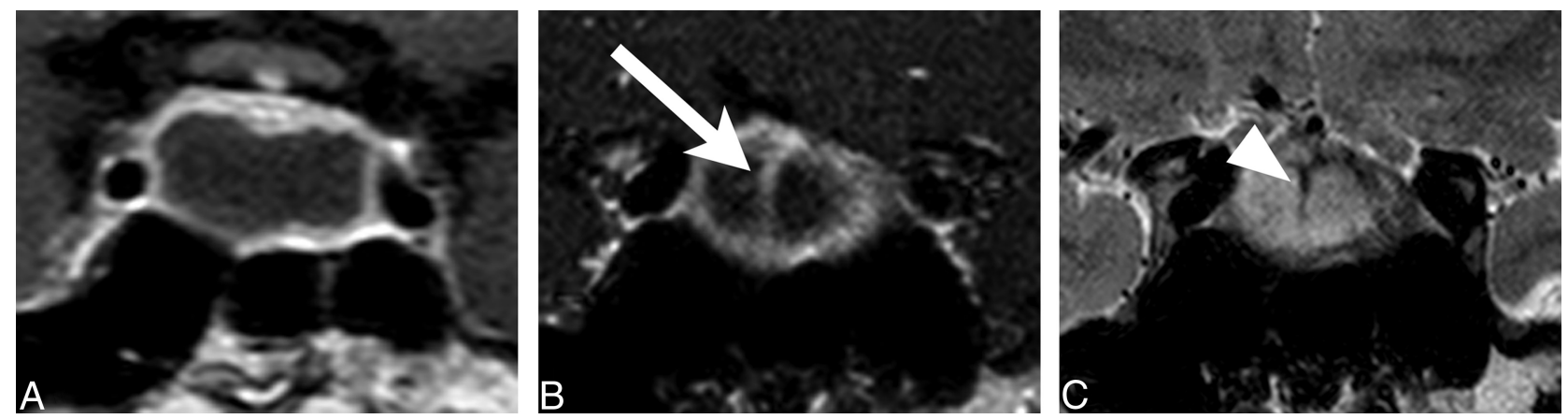

FIG 7. A 19 -year-old man presented with a nonenhancing intrasellar lesion with a midline location $(A)$ and internal septation ( $B$ [arrow] and $C$ [arrowhead]) on coronal contrast-enhanced T1-weighted imaging ( $A$ and $B)$ and coronal T2-weighted imaging (C). There was no visible fluid-fluid level or intracystic nodule, so this lesion was classified as a cystic pituitary adenoma based of the diagnostic tree model; however, it was finally diagnosed as a Rathke cleft cyst.

RCCs. Our diagnostic tree model exhibited good performance in both the study population and the external validation group; however, further study with a large number of patients may be needed to investigate the quality of the developed classifier.

\section{CONCLUSIONS}

We found that the presence of a fluid-fluid level, septation, an off-midline location, and the absence of an intracystic nodule were important imaging features for differentiating cystic pituitary adenomas from RCCs. The proposed diagnostic tree model using preoperative MR imaging increases the diagnostic accuracy for differentiating cystic pituitary adenomas from RCCs and may serve as a helpful tool for guiding disease management.

\section{REFERENCES}

1. Gutenberg A, Larsen J, Lupi I, et al. A radiologic score to distinguish autoimmune hypophysitis from nonsecreting pituitary adenoma preoperatively. AJNR Am J Neuroradiol 2009;30:1766-72 CrossRef Medline

2. Rennert J, Doerfler A. Imaging of sellar and parasellar lesions. Clin Neurol Neurosurg 2007;109:111-24 CrossRef Medline

3. Johnsen DE, Woodruff WW, Allen IS, et al. MR imaging of the sellar and juxtasellar regions. Radiographics 1991;11:727-58 CrossRef Medline

4. Zhang X, Zhang W, Fu LA, et al. Hemorrhagic pituitary macroadenoma: characteristics, endoscopic endonasal transsphenoidal surgery, and outcomes. Ann Surg Oncol 2011;18:246-52 CrossRef Medline

5. Semple PL, Webb MK, de Villiers JC, et al. Pituitary apoplexy. Neurosurgery 2005;56:65-72; discussion 72-73 Medline

6. Piotin M, Tampieri D, Rüfenacht DA, et al. The various MRI patterns of pituitary apoplexy. Eur Radiol 1999;9:918-23 CrossRef Medline

7. Tosaka M, Sato N, Hirato J, et al. Assessment of hemorrhage in pituitary macroadenoma by $\mathrm{T} 2^{\star}$-weighted gradient-echo MR imaging. AJNR Am J Neuroradiol 2007;28:2023-29 CrossRef Medline

8. Kurihara N, Takahashi S, Higano S, et al. Hemorrhage in pituitary adenoma: correlation of MR imaging with operative findings. Eur Radiol 1998;8:971-76 CrossRef Medline

9. Wang SS, Xiao DY, Yu YH, et al. Diagnostic significance of intracystic nodules on MRI in Rathke's cleft cyst. Int J Endocrinol 2012;2012: 958732 Medline

10. Osborn AG. Osborn's Brain: Imaging, Pathology, and Anatomy. Salt Lake City, Utah: Amirsys Publishing; 2013

11. Byun WM, Kim OL, Kim D. MR imaging findings of Rathke's cleft cysts: significance of intracystic nodules. AJNR Am J Neuroradiol 2000;21:485-88 Medline

12. Choi SH, Kwon BJ, Na DG, et al. Pituitary adenoma, craniopharyn- gioma, and Rathke cleft cyst involving both intrasellar and suprasellar regions: differentiation using MRI. Clin Radiol 2007;62: 453-62 CrossRef Medline

13. Binning MJ, Gottfried ON, Osborn AG, et al. Rathke cleft cyst intracystic nodule: a characteristic magnetic resonance imaging finding. J Neurosurg 2005;103:837-40 CrossRef Medline

14. Brassier G, Morandi X, Tayiar E, et al. Rathke's cleft cysts: surgicalMRI correlation in 16 symptomatic cases. J Neuroradiol 1999;26: 162-71 Medline

15. Wen L, Hu L-b, Feng X-y, et al. Rathke's cleft cyst: clinicopathological and MRI findings in 22 patients. Clin Radiol 2010;65:47-55 CrossRef Medline

16. Mehta GU, Jane JA Jr. Pituitary tumors. Curr Opin Neurol 2012;25 751-55 CrossRef Medline

17. Nishioka $\mathrm{H}, \mathrm{Haraoka} J$, Izawa $\mathrm{H}$, et al. Magnetic resonance imaging, clinical manifestations, and management of Rathke's cleft cyst. Clin Endocrinol 2006;64:184-88 CrossRef Medline

18. Saeki N, Sunami K, Sugaya Y, et al. MRI findings and clinical manifestations in Rathke's cleft cyst. Acta Neurochir (Wien) 1999;141: 1055-61 CrossRef Medline

19. Roelfsema F, Biermasz NR, Pereira AM. Clinical factors involved in the recurrence of pituitary adenomas after surgical remission: a structured review and meta-analysis. Pituitary 2012;15:71-83 CrossRef Medline

20. Goel A, Shah A, Jhawar SS, et al. Fluid-fluid level in pituitary tumors: analysis of management of 106 cases. J Neurosurg 2010;112:1341-46 CrossRef Medline

21. Buchfelder M, Schlaffer S. Surgical treatment of pituitary tumours. Best Pract Res Clin Endocrinol Metab 2009;23:677-92 CrossRef Medline

22. Barker FG 2nd, Klibanski A, Swearingen B, et al. Transsphenoidal surgery for pituitary tumors in the United States, 1996-2000: mortality, morbidity, and the effects of hospital and surgeon volume. J Clin Endocrinol Metab 2003;88:4709-19 CrossRef Medline

23. Connor SE, Penney CC. MRI in the differential diagnosis of a sellar mass. Clin Radiol 2003;58:20-31 CrossRef Medline

24. Bonneville F, Cattin F, Marsot-Dupuch K, et al. T1 signal hyperintensity in the sellar region: spectrum of findings. Radiographics 2006;26:93-113 CrossRef Medline

25. Jassal DS, McGinn G, Embil JM. Pituitary apoplexy masquerading as meningoencephalitis. Headache 2004;44:75-78 CrossRef Medline

26. Breiman L, Friedman J, Stone CJ, et al. Classification and Regression Trees. Belmont, California: Wadsworth International Group; 1984

27. Kucharczyk W, Davis DO, Kelly WM, et al. Pituitary adenomas: high-resolution MR imaging at 1.5 T. Radiology 1986;161:761-65 CrossRef Medline

28. Asari S, Ito T, Tsuchida S, et al. MR appearance and cyst content of Rathke cleft cysts. J Comput Assist Tomogr 1990;14:532-35 CrossRef Medline

29. Hua F, Asato R, Miki Y, et al. Differentiation of suprasellar nonneo- 
plastic cysts from cystic neoplasms by Gd-DTPA MRI. J Comput Assist Tomogr 1992;16:744-49 CrossRef Medline

30. Binning MJ, Liu JK, Gannon J, et al. Hemorrhagic and nonhemorrhagic Rathke cleft cysts mimicking pituitary apoplexy. J Neurosurg 2008;108:3-8 CrossRef Medline

31. Mohr G, Hardy J. Hemorrhage, necrosis, and apoplexy in pituitary adenomas. Surg Neurol 1982;18:181-89 CrossRef Medline

32. Poussaint TY, Barnes PD, Anthony DC, et al. Hemorrhagic pituitary adenomas of adolescence. AJNR Am J Neuroradiol 1996;17:1907-12 Medline

33. Bonneville JF, Bonneville F, Cattin F. Magnetic resonance imaging of pituitary adenomas. Eur Radiol 2005;15:543-48 CrossRef Medline

34. Amhaz HH, Chamoun RB, Waguespack SG, et al. Spontaneous in- volution of Rathke cleft cysts: is it rare or just underreported? J Neurosurg 2010;112:1327-32 CrossRef Medline

35. Shin JL, Asa SL, Woodhouse LJ, et al. Cystic lesions of the pituitary: clinicopathological features distinguishing craniopharyngioma, Rathke's cleft cyst, and arachnoid cyst. J Clin Endocrinol Metab 1999; 84:3972-82 CrossRef Medline

36. Kunii N, Abe T, Kawamo M, et al. Rathke's cleft cysts: differentiation from other cystic lesions in the pituitary fossa by use of singleshot fast spin-echo diffusion-weighted MR imaging. Acta Neurochir (Wien) 2007;149:759-69 CrossRef Medline

37. Zada G, Lin N, Ojerholm E, et al. Craniopharyngioma and other cystic epithelial lesions of the sellar region: a review of clinical, imaging, and histopathological relationships. Neurosurg Focus 2010; 28:E4 CrossRef Medline 